\title{
Comparison Research on Hydraulic Characteristics of Three Type's Orifice Plate
}

\author{
Tian-Ming Ding* and Yuanjiao Wang
}

Zhejiang Ocean University, Zhoushan, China

\begin{abstract}
Orifice plate, with the characteristics of high energy dissipation capacity and convenient construction, has a broad application prospects in China. It is revealed by the means of simulation in this paper that, under the condition of the same contraction ratio and thickness, sharp-edged orifice plate has the highest energy dissipation capacity and squareedged orifice plate has minimum energy dissipation ability among sharp-edged orifice plate, square-edged orifice plate and round-corner orifice plate. However, their capacities of resistance cavitations damage are vice versa. It is important to apply the most suitable shape orifice plate in practical engineering.
\end{abstract}

Keywords: Backflow region, comparison, energy loss coefficient, minimum pressure coefficient, orifice plate.

\section{INTRODUCTION}

With the development of hydropower projects, the heights of some dams have got to and exceeded the level of $300 \mathrm{~m}$, such as $305 \mathrm{~m}$ and $315 \mathrm{~m}$ for the Jinping firstcascade hydropower project and the Shuangjiangkou hydropower project respectively in Sichuan province, China. Over 30 hydropower projects with the height of over $100 \mathrm{~m}$ have been completed or under constructions since 2000 in China [1]. For a high dam project the energy dissipation for flood discharges is an important problem that affects the safety of this project directly [2]. The orifice plate as well as the plug, as a kind of energy dissipaters with sudden reduction and sudden enlargement forms, has been used in the hydropower projects due to its simple structure, convenient construction and high energy dissipation ratio. As early as 1960's last century, a plug dissipater, similar to orifice plate in energy dissipation mechanism, with the energy dissipation ratio of over $50 \%$, was used in the flood discharge tunnel of the Mica dam in Canada [3]. In 2000, a three-stage orifice plate was applied in the Xiaolangdi Projects in china, gets the energy dissipation ratio of about $44 \%$ and controlled effectively the flow velocity through the gate less than $35 \mathrm{~m} / \mathrm{s}$ under the condition of the head of 145 $\mathrm{m}[4]$.

Many researches were conducted on the energy dissipaters with sudden reduction and sudden enlargement forms. The interesting areas have been focused on energy loss characteristics and cavitations characteristics. The contraction ratio $(\beta)$, defined as the ratio of the orifice diameter $(d)$ of the energy dissipater and the diameter $(D)$ of flood discharge tunnel, is an important index affecting all the hydraulic characteristics. $\mathrm{Li} \mathrm{[2]} \mathrm{and} \mathrm{Wu}$ [5] deemed that the energy loss coefficient, relating to energy dissipation ratio, increased with the decrease of the contraction ratio. The less is the contraction ratio, the larger is the energy loss coefficient. In terms of orifice plate's incipient cavitations number, relating closely with tunnel's safety, it is also mainly dominated by contraction ratio. $\mathrm{Ni}[6]$ regarded that the incipient cavitations number of the orifice plate decreased with the increase of the contraction ratio. Ai [7] regarded when Reynolds number is more than $10^{5}$, Reynolds number has little effects on orifice plate's hydraulic characteristics.

As stated above, the researches conducted in the past focused mainly on the trend relationship between contraction ratio and energy loss coefficient or incipient cavitations number [8-10]. However, in addition to contraction ratio, orifice plate's geometry also has important effects on its hydraulic characteristics. So it is necessary to study geometry's effects on orifice plate's hydraulic characteristics. There are many types orifice plate, such as square-edged orifice plate, sharp-edged orifice plate, roundcorner orifice plate and so on. The above three type orifice plates' geometry is shown in Fig. (1). The purposes of the present work, therefore, are to investigate the effects of the geometric parameters, and to compare hydraulic characteristics of the above three type orifice plate. In relation to sharp-edged orifice plate and round-corner orifice plate, practice has proved that it is advantageous for orifice plate tunnel's structure when the top angle $\varphi$ is $60^{\circ}$ [11], so for the researched sharp-edged orifice plate and round corner orifice plate in this paper, their top angle $\varphi$ is also $60^{\circ}$.

\section{DEFINITION OF RELATING PARAMETERS}

Orifice energy loss coefficient can be defined as the following [11]:

$a=\Delta p /\left(0.5 \rho u^{2}\right)$

where $a$ is energy loss coefficient; $\Delta p$ is the pressure difference between the section before $0.5 D$ ( $D$ is tunnel's 


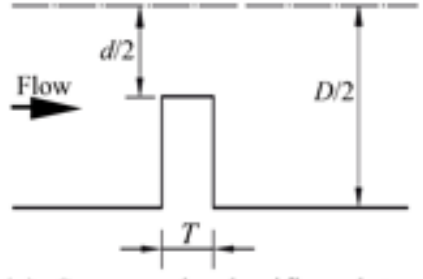

(a) Square-edged orifice plate

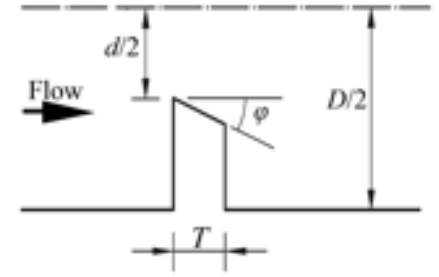

(b) Sharp-edged orifice plate

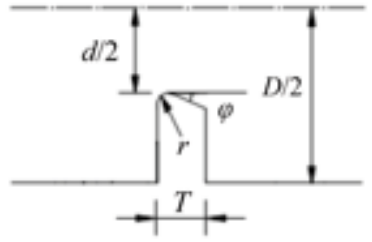

(c) Round-corner orifice plate

Fig. (1). Geometry of orifice plate.

diameter) orifice plate, in which flows are undisturbed, and the section after $3.0 \mathrm{D}$ orifice plate, where flows already recover; $\rho$ is flow's density; $u$ is flow's average velocity in discharge tunnel. Because cavitations first occurs at the lowest pressure place, the minimum wall pressure coefficient can indirectly illuminate the capacity of orifice plate tunnel resistance cavitations damage [12]. The minimum wall pressure coefficient is defined as:

$C_{\min }=\frac{p_{1}-p_{\min }}{0.5 \rho u^{2}}$

where $p_{1}$ is the average pressure of the section, which is located before $0.5 \mathrm{D}$ orifice plate; $p_{\min }$ is the minimum wall pressure around orifice plate.

\section{NUMERICAL SIMULATIONS MODEL}

The RNG $\mathrm{k} \sim \varepsilon$ model was used to calculate the hydraulic parameters of the flow through the orifice plate, due to its suitability for simulating the flow inside large change boundary forms as well as its high precision and calculation stability. For the steady and incompressible flows, the governing equations of this model can be written as [13]:

Continuity equation:

$\frac{\partial u_{i}}{\partial x_{i}}=0 \quad i=1,2$

Momentum equation:

$u_{j} \frac{\partial u_{i}}{\partial x_{j}}=-\frac{1}{\rho} \frac{\partial p}{\partial x_{i}}+\frac{\partial}{\partial x_{j}}\left[\left(v+v_{t}\right)\left(\frac{\partial u_{i}}{\partial x_{j}}+\frac{\partial u_{j}}{\partial x_{i}}\right)\right] i=1,2$

$k$-equation:

$u_{i} \frac{\partial k}{\partial x_{i}}=\frac{\partial}{\partial x_{j}}\left[\alpha_{k}\left(v+v_{t}\right) \frac{\partial k}{\partial x_{j}}\right]+\frac{1}{\rho} G_{k}-\varepsilon i=1,2$

$\varepsilon$-equation:

$$
u_{i} \frac{\partial \varepsilon}{\partial x_{i}}=\frac{\partial}{\partial x_{j}}\left[\alpha_{\varepsilon}\left(v+v_{t}\right) \frac{\partial \varepsilon}{\partial x_{j}}\right]+\frac{1}{\rho} C_{1}^{*} G_{k} \frac{\varepsilon}{k}-C_{2} \frac{\varepsilon^{2}}{k} i=1,2
$$

where $x_{i}(=x, y)$ are the coordinates in longitudinal and transverse directions, respectively; $u_{i}\left(=u_{x}, u_{y}\right)$ are the velocity components in $x$ and $y$ directions, respectively; $\rho$ is the density of water; $p$ is the pressure; $v$ is the kinematics viscosity; $v_{t}$ is the eddy viscosity and can be given by $v_{t}=$ $C_{\mu}\left(k^{2} / \varepsilon\right)$, in which $k$ is the turbulence kinetic energy, $\varepsilon$ is the dissipation rate of $k$ and $C_{\mu}=0.085$. The other parameters are: $C_{1}^{*}=C_{1}-\frac{\eta\left(1-\eta / \eta_{0}\right)}{1+\lambda \eta^{3}}, \eta=S k / \varepsilon, S=\frac{1}{2}\left(\frac{\partial u_{i}}{\partial x_{j}}+\frac{\partial u_{j}}{\partial x_{i}}\right), C_{1}$ $=1.42, \eta_{o}=4.377, \lambda=0.012, G_{k}=\rho v_{t}\left(\frac{\partial u_{i}}{\partial x_{j}}+\frac{\partial u_{j}}{\partial x_{i}}\right) \frac{\partial u_{i}}{\partial x_{j}}, C_{2}$ $=1.68$ and $\alpha_{k}=\alpha_{\varepsilon}=1.39$. The calculation boundary conditions are treated as follows: in the inflow boundary the turbulent kinetic energy $k_{\text {in }}$ and the turbulent dissipation rate $\varepsilon_{\text {in }}$ can be defined as respectively [14]:

$k_{\text {in }}=0.0144 u_{\text {in }}^{2}, \varepsilon_{\text {in }}=k_{\text {in }}^{1.5} /(0.25 D)$

where $u_{\text {in }}$ is the average velocity in the inflow boundary. In the outflow boundary the flow is considered as developed fully. The wall boundary is controlled by the wall functions. And the symmetric boundary condition is adopted, that is, the radial velocity on symmetry axis is zero.

The calculation tunnel's diameter is $0.21 \mathrm{~m}$, the average flow velocity in tunnel is $1 \mathrm{~m} / \mathrm{s}$ and Reynolds number is $1.8 \times 10^{5}$, Reynolds number is more than $10^{5}$, so Reynolds number's effects on energy loss coefficient and minimum wall pressure coefficient can be neglected. Because the orifice plate tunnel has axial symmetry characteristics, three dimensional numerical simulations of orifice plate tunnel flows can be simplified as two dimensional numerical simulations of orifice plate tunnel flows. The 3-D coordinate axis of orifice plate tunnel is shown in Fig. (2). In this paper, flows' characteristics of plane $\mathrm{XZ}$ are researched; 
the characteristics of flows in plane $\mathrm{XZ}$ can represent the whole orifice plate tunnel flows characteristics.

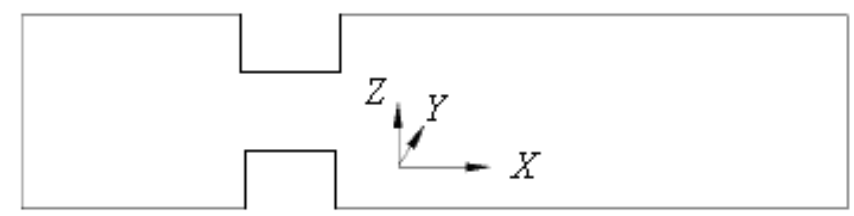

Fig. (2). 3-D coordinate axis of orifice plate tunnel.

\section{DISCUSSIONS}

\subsection{Comparisons on Backflow Region Length}

Fig. (3) is obtained by simulation when square-edged orifice plate's $\beta$ is 0.4 and $T / D$ is $0.25(T$ is orifice plate's thickness), which illuminates that there exists backflows area after orifice plate. Because flows turbulence and whirl severely in backflows area, backflows area is important energy dissipation source. Fig. (4), where $l_{b}=L / D$ and $L$ is backflow region's length, is the comparison results of three types of orifice plate's backflow region length when $T / D$ is 0.25 . It can be learned from Fig. (4) that, sharp-edged orifice plate's backflow region length is longest, square-edged orifice plate's backflow region length is shortest, and roundcorner orifice plate's backflow region length is middle under the condition of same contraction ratio and same thickness. The above conclusions also demonstrate indirectly that sharp-edged orifice plate's energy dissipation capacity is strongest, square-edged orifice plate's energy dissipation capacity is worst, and round-corner orifice plate's energy dissipation capacity is middle under the condition of same contraction ratio and same thickness.

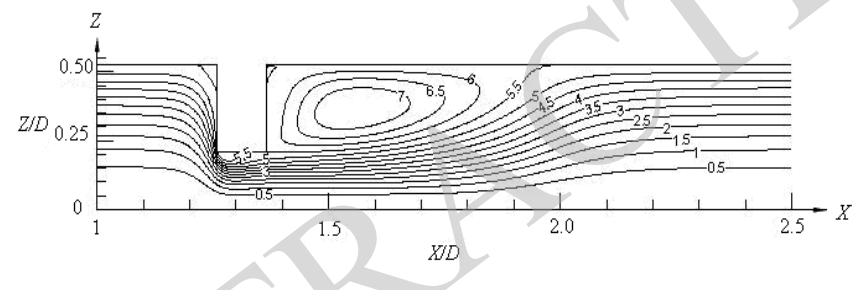

Fig. (3). Square-edged orifice plate's backflows $(\beta=0.4, T / D=0.25)$.

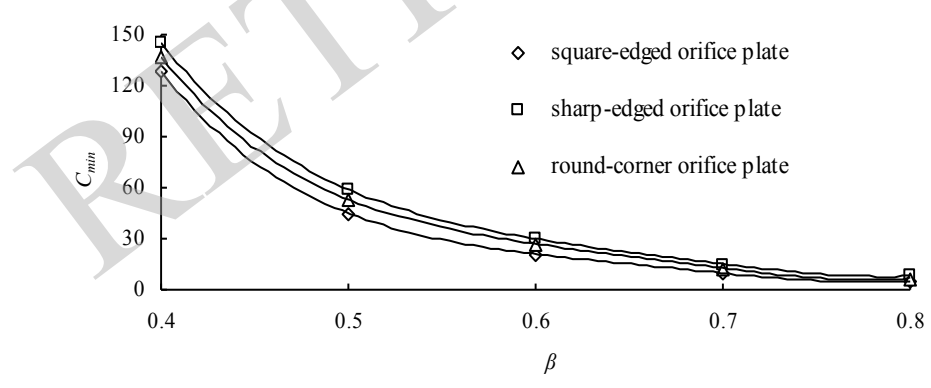

Fig. (4). Comparisons on backflow length of three orifice plate.

\subsection{Comparisons on Energy Dissipation}

Fig. (5) shows the comparison results about energy loss coefficient when $T / D$ is 0.25 . Fig. (5) demonstrates that orifice plate's energy dissipation capacity decreases with the increase of contraction ratio. Fig. (5) also illuminates that sharp-edged orifice plate's energy dissipation capacity is strongest, square-edged orifice plate's energy dissipation capacity is worst, and round-corner orifice plate's energy dissipation capacity is middle under the condition of same contraction ratio and same thickness. The clause deriving the above phenomenon is that, under the condition of same contraction ratio and same thickness, the three types of orifice plates' backflow region length are different.

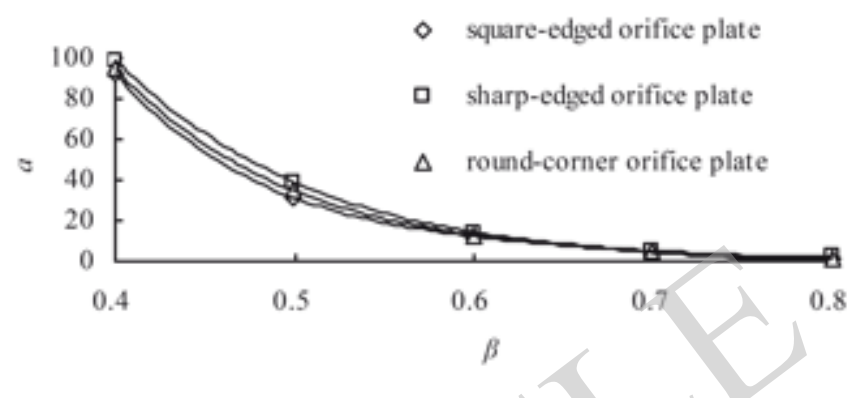

Fig. (5). Comparisons on energy loss coefficient.

\subsection{Comparisons on Minimum Wall Pressure}

Fig. (6) shows the comparison results about minimum wall pressure coefficient when $T / D$ is 0.25 . From Fig. (6), it can be learned that orifice plate's minimum wall pressure coefficient decreases with the increase of contraction ratio. Because minimum wall pressure coefficient reflects orifice plate's resistance cavitations damage capacity, orifice plate's resistance cavitations damage capacity increases with the decrease of minimum wall pressure coefficient, Fig. (6) demonstrates indirectly that orifice plate's resistance cavitations damage capacity increases with the decrease of contraction ratio. Fig. (6) also illuminates that square-edged orifice plate's resistance cavitations damage capacity is best, sharp-edged orifice plate's resistance cavitations damage capacity is worst, and round-corner orifice plate's resistance cavitations damage capacity is middle under the condition of same contraction ratio and same thickness.

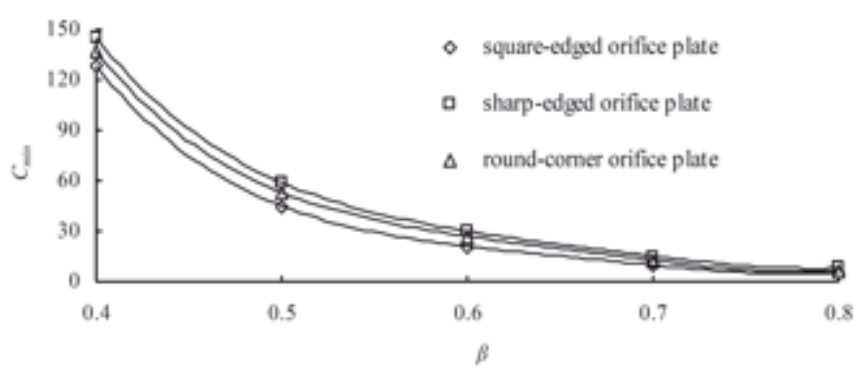

Fig. (6). Comparisons on minimum wall pressure coefficient.

\section{CONCLUSION}

By using simulation method, comparison researches on backflow length, energy loss coefficient and minimum wall pressure coefficient among square-edged orifice plate, sharpedged orifice plate and round-corner orifice plate have been conducted in this paper. Research results show that sharpedged orifice plate has the highest energy dissipation capacity and square-edged orifice plate has minimum energy dissipation ability, their capacities of resistance cavitations damage are vice versa under the condition of the same contraction ratio and thickness. 


\section{CONFLICT OF INTEREST}

The authors confirm that this article content has no conflict of interest.

\section{ACKNOWLEDGEMENTS}

Declared none.

\section{REFERENCES}

[1] Zhou, J.P.; Yang, Z.Y.; Chen, G.F. Status and challenges of high dam in China. J. Hydraul. Eng., 2006, 37(12), 1433-1438. (in Chinese)

[2] Li, Z.Y.; Chen, X.; Chen, M.F. Study on hydraulic problems of spillway tunnels with orifices reformed from diversion tunnel. $J$. Hydraul. Eng., 1997, 2, 1-10. (in Chinese)

[3] Russell, S.O.; Ball, J.W. Sudden-enlargement energy dissipator for Mica dam. J. Hydraul. Div, ASCE, 1967, 93(4), 41-56.

[4] Wu, J. H.; Ai, W.Z. Flows through energy dissipaters with sudden reduction and and sudden enlargement forms. J. Hydrodyn. Ser. B, 2010, 22(3), 234-345.

[5] Wu, J.H.; Ai, W.Z.; Zhou, Q. Head loss coefficient of orifice plate energy dissipaters. J. Hydraul. Res., 2010, 48(4), 526-530.
[6] Ni, H.G. Estimation of incipient cavitation number of spillway tunnel with orifice. J. Hydrodyn. Ser. A, 1995, 10(4), 419-429. (in Chinese)

[7] Ai, W.Z.; Ding, T.M. Orifice plate cavitation mechanism and its influencing factors. J. Water Sci. Eng., 2010, 3(3), 321-330.

[8] Xu, F.S.; Liu, S.J. The characteristics of multi-stage orifice plate. $J$. Hydraul. Eng., 1988, 11, 47-57. (in Chinese)

[9] Liu, S.J.; Yang, Y.Q.; Xu, W.L.; Wang, W. Hydraulic characteristics of throat-type energy dissipater in discharge tunnels. J. Hydraul. Eng., 2002, 7, 42-50. (in Chinese)

[10] Tian, Z.; Xu, W.L.; Wang, W.; Liu, S.J. Hydraulic characteristics of plug energy dissipater in flood discharge tunnel. J. Hydrodyn. Ser. B, 2009, 21(6), 799-806.

[11] Zhang, J.M.; Xu, W.L.; Liu, S.J.; Wang, W. Numerical simulation of turbulent flow in throat type energy dissipaters. J. Hydraul. Eng., 2004, 12, 27-39. (in Chinese)

[12] Qu, J.X.; Yang, Y.Q.; Zhang, J.M.; Xu, W.L. Numerical simulation of cavitation on orifice energy-dissipator. J. Sichuan Univ. (Eng. Sci. Ed.), 2001, 33(3), 30-36. (in Chinese)

[13] Qu, J.X.; Xu, W.L.; Yang, Y.Q. Numerical simulation of flow through orifice energy dissipaters in XIAOLANGDI flood discharge tunnel. J. Hydrodyn. Ser. B, 2000, 3, 41-46.

[14] Xia, Q.F.; Ni, H.G. Numerical simulation of plug energy dissipater, J. Hydraul. Eng., 2003, 8, 37-47. (in Chinese)

This is an open access article licensed under the terms of the Creative Commons Attribution Non-Commercial License (http://creativecommons.org/licenses/by-nc/3.0/) which permits unrestricted, non-commercial use, distribution and reproduction in any medium, provided the work is properly cited. 